\title{
Post-disaster reconstruction in the rural-urban fringe following the Great East Japan Earthquake
}

\author{
Kenji Muroi*
}

Department of Social and Human Environment, Nagoya University Graduate School of Environmental Studies, Furo-Cho Chikusa Nagoya 464-8601, Japan

\begin{abstract}
Although many studies have been conducted since the Great East Japan earthquake, most have focused only on recovery processes in particular affected areas. However, southern Miyagi Prefecture belongs to the rural-urban fringe of the Sendai Metropolitan Area; hence, disaster reconstruction in this area is closely related to the urban system and long-term land development. Based on these ideas, this paper explores the interaction between wider social trends and the disaster reconstruction process. The results indicate that disaster reconstruction in this area was an extension and acceleration of existing social trends such as "selection and concentration" and "intensification of agricultural competitiveness" as a whole. However, there is a unique agricultural land-use system and related community organization rooted in the peculiar history and environmental conditions of this area. Existing disaster reconstruction policies do not pay sufficient attention to such historical contexts, which has caused several conflicts and problems. Disaster studies should pay careful attention to such tensions between wider political trends and local historical contexts while focusing on land-use changes.
\end{abstract}

\section{Framework and Focus}

The purpose of this paper is to elucidate social changes following the Great East Japan earthquake of March 11, 2011. I would like to begin by outlining this study's analytical framework.

Disaster reconstruction studies involve two types of frameworks. The first type focuses on policies and activities during the reconstruction process in the affected areas. In this type of study, theoretical attention has been paid to dilemmas in the context of recovery [1]. In the Japanese context, this type of study often utilizes the dichotomy between the national government and local communities. The disaster reconstruction approach in Japan is characterized as central-government-initiated and technology-dependent. That is, the Japanese approach to disaster is "top-down" wherein many decisions are deferred to higher levels in the hierarchy before municipal governments can act [2,3]. Accordingly, in the case of the Great East Japan earthquake, the central government created a basic framework for reconstruction projects and provided enormous financial support for each. Although this "supply-side" reconstruction approach led to a remarkable upsizing of projects, it did not necessarily match the local needs in affected areas. Such discrepancies between supply and demand have been critically examined through case studies focusing on particular affected areas, yielding many research findings (although most are in Japanese) $[4,-8]$.
The second type of analytical framework focuses on the relationship between the disaster reconstruction process and long-term social trends. As Mitchell pointed out, every hazard is situated in a wider social context and thus hazard management is constrained by exogenous socio-economic factors [9]. This wider spatio-temporal analytical framework is useful not only for disaster studies but also for community and regional studies in general in that disasters often reveal structural principles and their contradictions in current society, which are overlooked during normal periods of time [10-12]. Although 3.11: Disaster and Change in Japan by R. J. Samuels was a remarkable achievement in this respect [13], this type of study is rare. Ten years after the earthquake, the lessons from its aftermath should be reconsidered from a broad perspective.

Accordingly, this study aims to explore the characteristics of and challenges to disaster recovery from a wider viewpoint, focusing on general social trends. Specifically, I emphasize the following perspectives in the analysis.

First, I focus on the impact of regional urban systems on disaster recovery processes in particular municipalities. Here, I am using the concept of urban system in Gottmann's sense to refer to "megalopolis," the growing interconnection of cities [14]. Our research area is in the southern part of Miyagi Prefecture, in the Sendai Metropolitan Area. Compared to the northern coastal area (Sanriku region), a fishery area that adjoins the Ria coastline, industrial development and

\footnotetext{
${ }^{*}$ Corresponding author: muroi.kenji@j.mbox.nagoya-u.ac.jp
} 
urbanization are more advanced in the south. Therefore, a viewpoint focusing on urban systems has particular significance in our study.

Second, a historical perspective is also important. The southern coastal area is located on the Sendai Plain and has long been an agricultural production site in the suburbs of Sendai city. Urbanization in this area followed agricultural land development. Although there is a distinction between urban studies and rural studies in current academic disciplines, such a distinction is not clear in the rural-urban fringe, as in our research areas. In fact, as described below, focusing on the rural roots of urbanization is of great importance in understanding the reconstruction process in this area.

Third, I focus on the reconstruction policies of municipal governments. Although centralization is a basic characteristic of the Japanese risk management system, as mentioned above, local governments also have political autonomy to a certain extent. Next, I explore the reconstruction policies of municipalities as one of the important independent variables and identify regional differences in disaster reconstruction due to such factors.

The discussion in this paper is based on a case study of Watari and Yamamoto, which are towns in Miyagi. Both municipalities are on the periphery of the Sendai Metropolitan Area and hence are suitable examples to illustrate the contradictory interaction between urban land use and agricultural land use in the process of disaster reconstruction. Our research is based on detailed interviews with community leaders of both towns and analysis of various statistics and official documents, such as the minutes of local council meetings. We also conducted a survey in 2018 on community reconstruction in Miyagi Prefecture ${ }^{1)}$. Our findings were derived from a comprehensive analysis of these multiple data sources.

The remainder of this paper proceeds as follows. First, I briefly examine the history of development in this area since the period of high economic growth as a social context for the 3.11 earthquake. Next, I examine the relationship between disaster reconstruction processes and regional urban systems, focusing on the characteristics of the population change after the disaster and the reconstruction policies in Yamamoto. Then, I examine changes in agricultural land use and related challenges. Finally, I reconsider the relationship between disaster reconstruction and long-term social trends in the context of the rural-urban fringe.

\section{Development in the pre-disaster period}

The southern coastal area in Miyagi is a low-lying flatland surrounded by the Pacific Ocean and the Abukuma River. Although the soil in the floodplain is suitable for agriculture, the low-lying coastal land experiences frequent flooding and used to be a vast wetland. Thus, improving agricultural drainage has been a long-standing challenge.

In the wake of post-war food shortages, the central government conducted large-scale irrigation and drainage projects from 1952 to 1971 . More than 4,000 ha of wet rice paddies in low-lying areas in Watari and Yamamoto were converted to dryland fields during this project [16]. Further, the mechanization of agriculture and farmland consolidation were promoted also from the 1960s, and accordingly, agricultural productivity and farm management improved drastically [17-20].

The accomplishment of the goals of these agricultural development projects was followed closely by the commencement of new industrial development projects. As the Sendai Bay coastal area was designated one of the "new industrial cities" by the National Comprehensive Development Plan in 1964, industrial and transportation development projects were heavily promoted. During the early stages of development, the populations of Watari and Yamamoto decreased because both towns were separated from the Sendai urban area by the Abukuma River, which made commuting to urban areas quite difficult. However, the frequency of service and number of cars per train increased in the late $1960 \mathrm{~s}$, and several new stations were constructed in the 1980s [19]. With the improved commuting facilities, the populations of Watari and Yamamoto began to increase in the 1970s. Expressway and bridge-building projects were also promoted by the government from the 1980s. The Sendai Metropolitan Area was directly connected to the Tokyo Metropolitan Area by a highway in 2009. The Sendai Airport Line was developed in 2007, improving air connectivity. Such drastic traffic development meant that each municipality in the southern coastal area became a metropolitan hub, with all of them well-connected to each other across multiple transport networks.

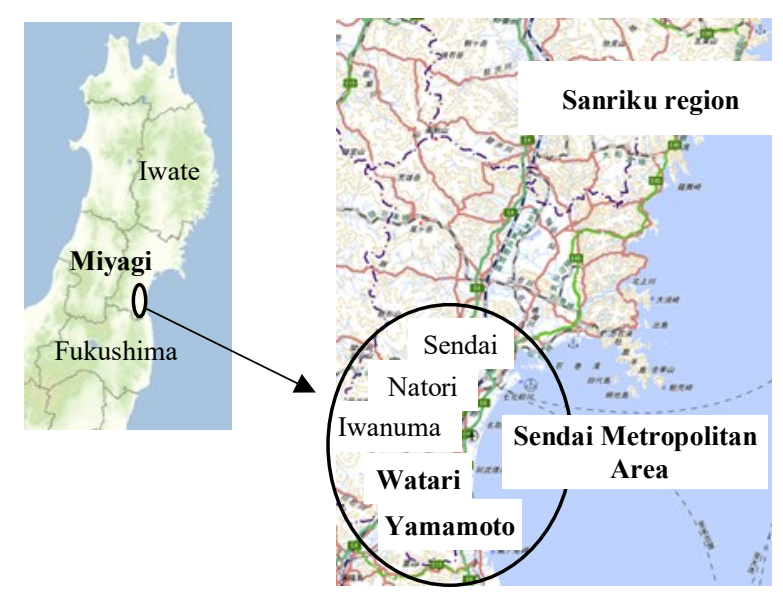

Fig. 1. Research area.

Source: Geospatial information authority of Japan.

The mechanization of agriculture contributed to a decline in the farming population as well as in agricultural development. For example, the ratio of workers in the primary industry in Watari declined from $68.5 \%$ in 1955 to $9.3 \%$ in 2010 . Similarly, industrial development in the coastal areas had an adverse impact on the fishery industry, leading to its decline. By contrast, the commuter population increased drastically. The ratio of workers in Watari and Yamamoto who commuted to other municipalities reached $65.1 \%$ and 
$58.9 \%$, respectively, in 2010; and their workplaces were mostly in Sendai and neighboring cities.

Against the backdrop of the expansion of the Sendai Metropolitan Area from the 1990s, housing land development advanced sporadically in the form of commuter towns. Thus, growing land-use change and social differentiation in the rural communities in the southern coastal area formed the social context in which the Great East Japan earthquake occurred.

\section{Damage and population change}

In this section, I will examine the characteristics of the damage and population change caused by the earthquake in the southern coastal area.

There are differences in the damage caused by the earthquake and tsunami in the Sanriku region from that in the southern coastal area. In particular, the damage caused by the tsunami was much greater in the Sanriku region than in the southern area. The impacts of a tsunami may vary depending on the scale of the seismic movement and the geographical features of the coastline. Thus, the Sanriku's complicated rocky coastline created a higher tsunami than in the southern coastal area, which led to greater damage and loss of life. Business centers and public facilities were also heavily damaged in the Sanriku region because urban functions were concentrated in coastal areas.

Meanwhile, the characteristics of damages in the south were as follows: First, the tsunami caused serious agricultural losses. While the tsunami inundation rate was less than 10\% in Sanriku municipalities, in the lowlying southern region, almost half of the municipal area was inundated. The coastal plain was mainly utilized for agriculture; hence, it suffered serious agricultural damage.

Second, the social impact of the damage to the railway line was far more serious in the south. Railway lines in the southern coastal area were partially swept away by the tsunami, obstructing commuting for an extended period of time. Although damage to the railway line in central cities such as Sendai, Natori, and Iwanuma was not significant, damage in peripheral areas like Watari and Yamamoto was much heavier, such that restoration of the railway required two years in the southern part of Watari and almost five years in Yamamoto.

The long-term suspension of commuting caused massive population outflows in both towns. In fact, population decreases following the earthquake in Watari and Yamamoto were caused not only by deaths and persons gone missing due to the tsunami, and enforced relocation from high-risk areas, but also by voluntary migration due to the obstructions to commuting. As census data show, the areas they moved into were mostly Sendai and neighboring cities such as Natori and Iwanuma (Table 1). As a result, the population gap between the center and periphery of the Sendai Metropolitan Area expanded following the earthquake (Figure 2). Railway tracks suffered similar damage in the Sanriku region. However, the commuting population in Sanriku was much smaller; thus, the impact of railway service suspension was quite limited. Population changes caused by damage to commuting facilities are unique to disasters in urban areas.

Table 1. Changes in settlement sites (2010-2015).

\begin{tabular}{l|c|c}
\hline $\begin{array}{c}\text { Residence } \\
\text { in } 2010\end{array}$ & $\begin{array}{c}\text { Population } \\
\text { outflow }\end{array}$ & $\begin{array}{c}\text { Residence in 2015 } \\
\text { (ratio to population outflow) }\end{array}$ \\
\hline Watari & 3,848 & Sendai (24.8) Iwanuma (17.3) Natori (9.8) \\
Yamamoto & 3,405 & Watari (23.1) Sendai (21.5) Natori (10.1) \\
\hline
\end{tabular}

Source: National population census.

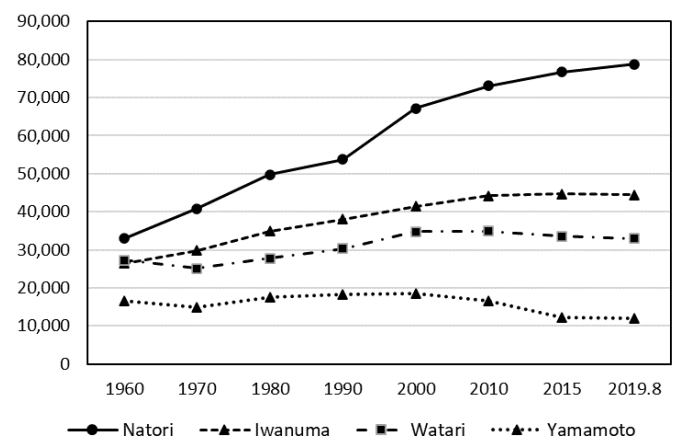

Fig. 2. Population trends.

Who remained and who moved out? Table 2 shows the population trends for coastal agricultural villages in Watari. Villages D and E were designated as risk areas; therefore, the number of households in these villages declined drastically after the earthquake. However, the population of villages $\mathrm{C}$ and $\mathrm{G}$ also decreased drastically after the earthquake. In these villages, the population increased rapidly in the $1990 \mathrm{~s}$. This was caused by small-scale housing development at that time, as mentioned in Section 2. This means that people who moved out after the earthquake were mostly newcomers from the 1990's.

Table 2. Change in the number of farming households by agricultural village.

\begin{tabular}{llcccc}
\hline & & 1990 & 2000 & 2010 & 2015 \\
\hline \multirow{2}{*}{ A } & Farmers & 39 & 36 & 29 & 31 \\
& Non-farmers & 36 & 47 & 53 & 66 \\
\hline \multirow{2}{*}{ B } & Farmers & 36 & 31 & 27 & 23 \\
& Non-farmers & 11 & 33 & 37 & 39 \\
\hline \multirow{2}{*}{ C } & Farmers & 79 & 68 & 49 & 20 \\
& Non-farmers & $\mathbf{8 2}$ & $\mathbf{1 4 6}$ & 155 & 88 \\
\hline \multirow{2}{*}{ D } & Farmers & 51 & 45 & 39 & 8 \\
& Non-farmers & 5 & 13 & 13 & 5 \\
\hline \multirow{2}{*}{ E } & Farmers & 44 & 41 & 36 & 7 \\
& Non-farmers & 11 & 67 & 69 & 33 \\
\hline \multirow{2}{*}{ F } & Farmers & 98 & 108 & 105 & 65 \\
& Non-farmers & 48 & 60 & 69 & 43 \\
\hline \multirow{2}{*}{ G } & Farmers & 52 & 48 & 32 & 24 \\
& Non-farmers & $\mathbf{4 9}$ & $\mathbf{1 0 4}$ & 110 & 53 \\
\hline \multirow{2}{*}{ H } & Farmers & 85 & 74 & 49 & 30 \\
& Non-farmers & $\mathbf{3 3 4}$ & $\mathbf{5 9 8}$ & 724 & 697 \\
\hline \multirow{2}{*}{ Source: Census data for agricultural villages. }
\end{tabular}

Source: Census data for agricultural villages.

This was supported by interview research in these villages. According to community leaders, while farmers remained in this area, most newcomers and commuters moved out. Although the population change in village $\mathrm{H}$ seems to be relatively small, it was because 
a new housing complex for group relocation was developed in this district. In actuality, a large number of newcomers in this village also moved away after the earthquake.

These findings show how the disaster revealed the differences between native farmers and middle-class newcomers with respect to ties to the land. As discussed later, this population decline mechanism was also confirmed in Yamamoto.

Such voluntary migration and group relocation projects due to the designation of disaster risk areas also caused an expansion in the disparity between inland and coastal areas in municipalities. Although the cause of the group relocation project was disaster risk reduction, it resulted in the concentration of urban functions in inland areas. Particularly in Yamamoto, as will be described in the next section, such consolidation of urban functions in central districts was intentionally promoted with the slogan of "compact city." In contrast, as the population declined, convenient facilities such as shops and hospitals withdrew and living conditions worsened remarkably in the coastal areas of Watari and Yamamoto.

From a broader perspective, living conditions after the earthquake worsened in the Sanriku region as a whole because of the promotion of relocation from urban coastal areas to inconvenient highlands. In contrast, living conditions in the south were significantly improved because of relocation (Table 3 ). Therefore, the disparity between the inland and coastal areas in the municipalities of the south tends to be underestimated in reconstruction policies. However, in Watari, where relatively many people remained in coastal areas, the living conditions worsened remarkably. In Yamamoto, although actual situations are not reflected in the quantitative data, the disparity between inland and coastal areas is higher, as will be discussed below.

Table 3. Changes in Living Conditions after the EQ.

\begin{tabular}{clccc} 
& \multicolumn{3}{c}{ Access to Shopping. } \\
\cline { 2 - 5 } North & $\begin{array}{c}\text { Became } \\
\text { better }\end{array}$ & No change & $\begin{array}{c}\text { Became } \\
\text { worse }\end{array}$ \\
\cline { 2 - 5 } & Kesennuma & 9.4 & 61.3 & 25.5 \\
& Minami sanriku & 9.1 & 30.3 & 60.6 \\
& Onagawa & 0 & 52.0 & 48.0 \\
\cline { 2 - 5 } South & Natori & 41.7 & 41.7 & 16.7 \\
& Iwanuma & 33.3 & 58.3 & 0.0 \\
& Watari & $\mathbf{0}$ & $\mathbf{3 6 . 4}$ & $\mathbf{5 4 . 5}$ \\
& Yamamoto & $\mathbf{2 5 . 0}$ & $\mathbf{6 2 . 5}$ & $\mathbf{1 2 . 5}$ \\
\hline
\end{tabular}

Access to Hospital.

\begin{tabular}{|c|c|c|c|c|}
\hline & & $\begin{array}{c}\text { Became } \\
\text { better }\end{array}$ & No change & $\begin{array}{c}\text { Became } \\
\text { worse }\end{array}$ \\
\hline \multirow{3}{*}{ North } & Kesennuma & 11.3 & 60.4 & 24.5 \\
\hline & Minami sanriku & 15.2 & 30.3 & 54.5 \\
\hline & Onagawa & 0 & 60.0 & 40.0 \\
\hline \multirow{4}{*}{ South } & Natori & 33.3 & 58.3 & 8.3 \\
\hline & Iwanuma & 0 & 91.7 & 8.3 \\
\hline & Watari & $\mathbf{0}$ & 27.3 & 72.7 \\
\hline & Yamamoto & 6.3 & 87.5 & 6.3 \\
\hline
\end{tabular}

Source: See note 1 .

\section{Disaster reconstruction as an urban renewal project}

Regarding disaster reconstruction policies following the earthquake, the following basic characteristics can be observed: First, safety against tsunamis was strongly emphasized, and large-scale disaster prevention projects were aggressively promoted [15]. Specifically, while huge seawall construction and land elevation works were conducted in coastal areas, residents were prohibited from living in their original homes in areas designated as risk-prone. In addition, large-scale relocation projects were promoted. Second, a "build back better" policy was pursued. "Build back better" meant mainly economic development in the Japanese context, captured in the declaration "Towards Reconstruction: Hope Beyond Disaster" presented by the Reconstruction Design Council for the Great East Japan earthquake. This declaration emphasized both the reconstruction of afflicted areas and the revitalization of the national economy through disaster reconstruction. Based on these ideas, the government provided huge financial support; hence, reconstruction projects tended to become bloated.

In terms of the response to disaster prevention policies, such as huge construction and relocation projects, there were obvious differences between the Sanriku region and the southern coastal areas. While active protests were held in several fishing villages in Sanriku because these projects were not compatible with the needs of fishing communities, there were few protests in the south because the fishery industry had already declined following industrial development after the 1960s. Meanwhile, "build back better" policies had a greater impact in the southern areas. In this respect, in this section, I will discuss the reconstruction projects in Yamamoto that pursued the "compact city" ideal as well as the changes in agricultural land use in the next section.

Unlike other affected municipalities, Yamamoto pursued not only the reconstruction of affected areas but also drastic urban restructuring with the slogan "compact city." Compact city policies in the Japanese context denote urban planning that promotes the concentration of urban functions in a few areas for the purpose of fiscal efficiency. Given the backdrop of depopulation and the fiscal crisis, "compact city" is now a key political strategy employed by many peripheral municipalities. The compact city project in Yamamoto was as follows: Damaged existing railway lines would be relocated and restored inland, and new stations would be created. A new city center would be built around these stations by promoting large-scale housing reconstruction projects and urban development.

According to the mayor, the city administration of Yamamoto had difficulty in efficiently managing autonomous bodies in the pre-disaster period because 22 villages were scattered throughout the town. As such, the city administration saw disaster reconstruction as an opportunity for drastic urban redevelopment for more efficient town management. The location of the new Yamashita train station was particularly convenient for its connection with National Route 6 and the Yamamoto 
interchange. The new Yamashita station area was thus regarded as an ideal base for a "compact city," and a large-scale shopping mall and several welfare facilities were developed there. As the scale of the disaster reconstruction project in Yamamoto was larger than that of neighboring municipalities, the city administration depended heavily on nationally subsidized projects like the Tsunami Reconstruction Base Development Project.

The main aim of this large-scale project was to cope with the estimated long-term trends of depopulation and aging in Yamamoto. Yamamoto is located at the southern end of the Sendai Metropolitan Area, furthest from Sendai City, and was placed in a disadvantageous position in the urban system. Presumably, it is assumed that the disaster reconstruction plan for Yamamoto was driven not only by disaster-related factors but also by the city administration's sense of crisis caused by the peripheral location of Yamamoto in the Sendai Metropolitan Area. In Yamamoto, therefore, the disaster reconstruction plan was developed as a new version of long-term comprehensive city planning. However, the disaster reconstruction plan gave rise to various disputes and conflicts.

The first issue was related to consensus-building regarding the adaptation to the existing system. As Yamamoto's mayor had previously been a crisis manager for Miyagi Prefecture, he was familiar with national disaster reconstruction institutions and initiatives. Under the existing legal system, most disaster recovery projects depend heavily on national subsidies. Thus, the mayor prioritized rapid adaptation to the existing system and made the following statement at a plenary meeting in December 2011:

If we cannot utilize national institutions properly, it is impossible to recover from this big disaster. We must work together on these tasks to meet the government's deadline. I think there will be no going back. I will make all possible efforts.

However, such a political stance meant that the mayor tended to neglect the opinions of the affected people. Yamamoto's reconstruction plan was made in December 2011, the fastest in Miyagi Prefecture. Before making the plan, the town administration conducted a survey among citizens regarding the basic vision for disaster reconstruction. However, people's opinions can change over time. The town administration's hurried decisions meant that it was indifferent to follow-up research. Such a political stance was repeatedly criticized in the town council, and a motion censuring the mayor's political stance was passed without objection in December 2013.

The second issue was population decline. The relocation project for the railway line was conducted not only for tsunami-related disaster prevention, but also with sustainable development in mind in an era of population decline and aging. However, this large-scale reconstruction project took much longer than the railway restoration projects in other municipalities. Ironically, therefore, the population decline accelerated during the long period of suspended railway operations. Specifically, it took 5 years and 9 months for the railway to restart, and the population decreased by $30 \%$ during this period.

Population decline was also caused by another political factor, that is, the scale of the designated risk area in Yamamoto. The standard risk areas in Iwanuma and Watari were estimated to have a tsunami inundation depth of two meters, whereas the standard in Yamamoto town was just over one meter. As a result, the risk area in Yamamoto Town encompassed 1945 ha, much greater than the 842 ha in Iwanuma and 545 ha in Watari. This large area designation was presumably based not only on the scientific simulation of tsunami inundation but also on the political judgment of the town administration. That is, the political incentive to accomplish successful group relocation to the new central district had an impact on the scale of the designated risk area. The fact that almost one-third of the town's territory was designated as a risk area, in which housing reconstruction was restricted, had a significant impact on the population outflow. Therefore, some people in the affected area raised objections to the town administration and submitted a petition for a reduction of the size of the risk area.

The third issue concerning disaster recovery was the increase in the disparity between districts in Yamamoto following the earthquake. While the administration of Yamamoto designated even areas in which the estimated tsunami inundation depth was less than two meters as risk areas, it still permitted residents to live in such areas under the requirement that they raise the ground level of their homes. However, the town administration prioritized the relocation of residents to the new central districts by providing additional financial support to people who chose to relocate. Residents who chose to remain in their original locations and undertook housing reconstruction objected to this selective support. Furthermore, while the administration built raised roads as part of the "multiple defense" policy for tsunami disaster mitigation, people who rebuilt their houses in risk areas were excluded from such protection and remained exposed to tsunami risks. After the construction of the new central districts was completed, remarkable disparities between existing districts and newly developed districts in services such as shopping and kindergarten became apparent.

The compact city project mainly targeted young households whose members commuted to the Sendai Metropolitan Area. The town administration actively promoted the relocation project with the slogan "Yamamoto town is the best place for child rearing." Meanwhile, the compact city project was not necessarily attractive to the older residents who had lived in rural areas for a long time, given what the changes in lifestyle, landscape, and neighborhood communities in newer urban developments would mean for them.

Why should people engaged in agriculture and fishery have to relocate to urban centers? It is pretty good for the people whose children commute to high school in Sendai City, to be sure, but.... We should have more diverse images of a compact city, which are in sync with Yamamoto Town, for example, a compact city with 
an ocean view and a compact city coexisting with agriculture....

--Statement by a council member at a plenary meeting in December 2013

Therefore, some people decided to remain in risk areas even though the population declined drastically and daily conveniences significantly worsened. Other people petitioned to relocate to places other than the designated new urban centers. In this sense, the compact city project in Yamamoto revealed conflicts of interest between social groups.

\section{Changes in agricultural land use}

As previously mentioned, tsunamis caused large-scale agricultural damage in the southern coastal areas, and tsunami-inundated farmland areas amounted to 1826 ha in Watari and 1416 ha in Yamamoto. Almost all agricultural facilities and machines were swept away.

The town administrations of Watari and Yamamoto promoted large-scale agricultural restoration projects. These projects pursued not only agricultural restoration, but also an increase in agricultural productivity. When the Great East Japan earthquake occurred, promoting large-scale farming and boosting Japan's agricultural competitiveness in the global market were priorities for national politics against the backdrop of the TransPacific Partnership (TPP) Agreement negotiations. In this political context, the Reconstruction Design Council proposed that agriculture in the southern coastal plain areas should be rebuilt as a "front runner of landextensive farming in Japan" and large-scale grant projects for agricultural reconstruction were introduced.

Based on this scheme, both the restoration and consolidation of farmland as well as the introduction of large-scale agricultural machines and facilities, were actively promoted in Watari and Yamamoto. The total cost of these projects added up to as much as 400 million dollars in each municipality.

As a result, the scaling up of agriculture progressed rapidly. Each unit of paddy field was successfully enlarged from 30 ares to 1 ha, and fragmented land holdings were agglomerated via farmland consolidation projects. Many farmers gave up farming after the damage caused by the earthquake and delegated their farmland cultivation to a handful of full-time farmers. Although contract farming had already progressed in the pre-disaster period, the trend accelerated after the earthquake. The area under cultivation per farmer was remarkably enlarged, and new large-scale full-time farmers appeared after the earthquake. Hence, the efficiency of agricultural production improved remarkably.
Table 4. Changes in agriculture.

\begin{tabular}{|c|c|c|c|c|}
\hline & & 2005 & 2010 & 2015 \\
\hline \multirow{3}{*}{$\begin{array}{c}\text { Watari } \\
\text { (coastal area) }\end{array}$} & $\begin{array}{l}\text { Operating cultivated } \\
\text { land (ha) }\end{array}$ & 641.5 & 705.1 & 628.1 \\
\hline & $\begin{array}{l}\text { Cultivated land } \\
\text { rented (ha) }\end{array}$ & 70.0 & 117.2 & 262.3 \\
\hline & Farm households & 316 & 294 & 164 \\
\hline \multirow{3}{*}{$\begin{array}{l}\text { Yamamoto } \\
\text { (coastal area) }\end{array}$} & $\begin{array}{l}\text { Operating cultivated } \\
\text { land (ha) }\end{array}$ & 785.4 & 760.9 & 357.2 \\
\hline & $\begin{array}{l}\text { Cultivated land } \\
\text { rented (ha) }\end{array}$ & 136.9 & 158.2 & 200.8 \\
\hline & Farm households & 400 & 325 & 83 \\
\hline
\end{tabular}

The southern coastal areas were a farmingresidential mixed zone before the earthquake. Following the disaster, however, reconstruction policies led to the concentration of urban functions in inland areas. Meanwhile, vast coastal land tracts left vacant due to relocation were utilized for large-scale agricultural development projects. Although relocation projects were promoted with the aim of disaster risk reduction, this functional differentiation of land use was closely interrelated with general political trends, such as "selection and concentration," and intensification of agricultural competitiveness had been pursued since the late 1990s because of financial deterioration and TPP negotiations. These political purposes were accomplished quite successfully in disaster reconstruction projects in the southern coastal areas.

However, rapid land-use changes gave rise to certain conflicts and contradictions as well. First, the community-based farmland management system disintegrated. To examine this issue in detail, let us take the case of Nakahama District in Yamamoto as an example. Nakahama was one of the most severely damaged districts in Yamamoto, where most of the land was designated as a risk area. Although the operating cultivated land in Nakahama was reduced from 144.7 ha in 2010 to 42.8 ha in 2015 , the number of farm households decreased from 61 to 5 , and the rate of cultivated land rentals increased from $38.9 \%$ to $89.5 \%$. This means that agricultural productivity in Nakahama improved drastically.

According to one of the large-scale full-time farmers, he rented various large-scale agricultural machines and facilities, such as tractors, combine harvesters, rice dryers, and so on, for free on the condition that he would cultivate large holdings of at least 35 ha for 10 years. As a result, the efficiency of agricultural production improved remarkably. However, he faced difficulties in mowing the grass on the footpaths between rice fields and in cleaning ditches. Before the earthquake such agricultural land maintenance was conducted collectively by the village. However, such village customs collapsed because of the decrease in the number of farmers. As large-scale agricultural machines were useless for mowing grass and cleaning ditches, he was forced to employ several people for such work. However, as the scale of farmland increased, farmland maintenance became much more difficult as well. In the face of this difficulty, the town administration prepared subsidies to call for 
participation in mowing grass; nevertheless, there were few participants, and the subsidies were refunded. As a result, the farmer was eventually forced to depend on herbicides.

The breakdown of collective farmland management not only constrained the further expansion of agricultural production, but also led to the disintegration of community cohesion. It has been pointed out that the collective activities of mowing grass and cleaning ditches are sources of communalities [21,22]. Customary practices of social gatherings after collective agricultural activities in Nakahama and other villages, such as "Ocha Nomi (tea parties)," disappeared after the earthquake. Under these circumstances, social welfare for isolated elderly people who are no longer practicing agriculture emerged as a new challenge (see Mochizuki 2020 for details) [23].

Agricultural reconstruction projects were rated highly by the town administrations of Watari and Yamamoto. The mayor of Iwanuma, for example, stated the following at a plenary meeting in March 2015:

Reconstruction of agriculture, the main industry of Watari, and of fisheries had good results all in all. ...Land consolidation of paddy fields reached $1123 \mathrm{ha}$. Infrastructural development for efficient agricultural management in international markets for agricultural commodities is making steady progress. I think agriculture in Watari will be a major source of employment and hence a growth industry.

However, there are discrepancies between this positive evaluation by the mayor and the actual situation of the farmers mentioned above.

Second, the management of coastal forests was undermined. Before the earthquake, coastal villages managed the seaside forest because it was indispensable for community life and agricultural production to mitigate the damage caused by high tides and storms. The tsunami caused by the 3.11 earthquake swept away the seaside forest, and most of the local residents left coastal areas due to relocation projects. Subsequently, Miyagi Prefecture proposed reforestation in collaboration with the private sector, and accordingly, an environmental non-profit organization (NPO) initiated the reforestation project backed by financial support from the government. This project was promoted based on the idea of environmental regeneration, and it attracted public attention. Over 5,000 people and various companies participated as environmental volunteers, and more than 40,000 trees were planted along $4 \mathrm{~km}$ of coastline over a span of three years. This reforestation project was rated highly and designated as a model project of "green decentralization reform" by the national government.

After the tree planting, however, the project stagnated because of a shortage of funds and manpower. In this project, the government paid attention only to tree planting, and subsidies were discontinued after the tree planting was finished. However, growing trees requires long-term maintenance. According to the members of the NPO, because tree planting is an attractive event related to environmental studies for school children and for corporate social responsibility or CSR activities, there were many such participants. However, regular maintenance of trees, such as undergrowth cutting and pruning, is not as attractive for such people; hence, the number of participants also decreased drastically. A few farmers remained in the coastal area, but they could not afford to cope with forest management due to the expansion of agricultural production. Although reforestation-related difficulties were brought up in the town council meetings, the town administration did not have a positive attitude because of financial concerns and unclear role divisions between the Town and the Prefecture. Against the backdrop of such difficulties, members of the NPO started to grow peanuts in abandoned farmland to gather funds for management activities; however, they had difficulties producing a good yield because they were not farmers.

Coastal forests have played a significant role in mitigating damage caused by blowing sand and storm surges in this area. Thus, customary management of the coastal forest, which is indispensable for agricultural production, became a "disaster subculture" [24] in this area. The case study mentioned above depicts the difficulties involved in replacing such a communitybased disaster subculture with environmental volunteer activities. Furthermore, while the government emphasized disaster prevention projects focusing only on tsunamis and efficient agricultural development, such reconstruction projects had negative outcomes with respect to disaster risk reduction in the coastal area due to their inattention to multifunctional rural villages.

Third, land use changes at relocation sites caused problems as well. The place where the reconstruction housing complex was built used to be paddy fields before the earthquake. As mentioned in Section 2, the affected areas in the south were low-lying areas; hence, agricultural drainage systems had been developed through long-term efforts and ingenuity. However, group relocation projects were promoted without sufficient attention to such historical contexts.

As a result, urban flooding occurred repeatedly at the relocation site in Watari. The place where the reconstruction housing complex was constructed used to be paddy fields before the earthquake. However, building lots were developed without proper connections to existing agricultural drainage channels, and thus floodwater overflowed from the reservoir around the housing complex. When one councilor mentioned the installation of drainage pumps after the flooding, the town administration rejected the argument because the reservoir was designed in accordance with the guidelines of the Prefecture.

In Yamamoto, as mentioned, group relocation projects were promoted as urban restructuring projects around newly constructed stations. During the reconstruction projects, however, it turned out that one of the relocation sites was in a potential tsunami inundation zone. To deal with this problem, the town administration planned to raise the foundation of the housing complex. However, although this land elevation work was beneficial for people who settled in the new housing complex, it might have caused new flooding risks for people who lived in nearby low-lying areas. 
Therefore, neighborhood community associations opposed the construction plan and submitted a petition to the town council. As a result, the project was delayed by almost a year.

In rural-urban fringes such as Watari and Yamamoto, urbanization has historically progressed in concert with agricultural land development. However, after the earthquake, housing complex construction projects followed by group relocation schemes were conducted by the Department of City Planning; hence, the reconstruction plan was made without sufficient attention to previous agricultural land use. As illustrated, the problems mentioned above were caused by contradictions between administrative rules and the historical contexts of land use in this area.

\section{Conclusion}

Although most studies on the Great East Japan earthquake have been case studies focusing on recovery processes in specific affected areas, this paper aimed to explore the interrelationships between long-term social trends and the disaster reconstruction process. Based on the analysis, I would like to highlight several points below.

First, there is an association between the urban system and disaster reconstruction. Previous studies have mainly examined housing reconstruction following group relocation projects after the EQ. However, our research revealed that a considerable number of people who had lived outside of the disaster risk area also voluntarily migrated to other areas. This population outflow was mainly caused by a disturbance in commuting due to railway line damage.

However, the root causes of the population decline after the EQ can be traced to regional urban development since the 1960s. In Watari, the majority of the newcomers from the 1990s left; hence, housing development that turned towns into bedroom communities in the pre-disaster period was closely connected with population changes after the EQ. Accordingly, reconstruction revealed differences between social strata in terms of ties with the land.

Disaster reconstruction in Yamamoto was a more extreme case. Although the urban renewal project in Yamamoto has been promoted with the aim of adapting to competitive urban systems, prolonged construction periods due to large-scale projects ironically caused a drastic population outflow. As a result, the population gap between the center and periphery in the Sendai Metropolitan Area and the gap in living conditions between coastal rural areas and inland city centers inside the municipalities have expanded interactively following the EQ.

Second, there is also a relationship between agricultural land use and disaster reconstruction. Disaster reconstruction policies following the EQ tended to prioritize economic development, with the slogan of "build back better," as well as technological disaster mitigation. In the context of agricultural reconstruction, such a tendency was prominent, and large-scale projects for the improvement of agricultural efficiency were strongly promoted. In contrast, the community-based farmland management system was disintegrated due to the advancement of contract farming and large-scale relocation projects. This led not only to a disturbance with respect to further development of agricultural production, but also to the disintegration of community cohesion. Furthermore, land use specialized only for efficient agricultural production led to a decline in disaster subculture, such as community-based management of disaster prevention coastal forests. The rapid conversion of paddy fields to residential lands in relocation sites has also caused urban floods.

In summary, disaster reconstruction in the ruralurban fringe was characterized by the concentration of urban functions in inland areas through large-scale relocation projects and large-scale agricultural development projects in the vast coastal land left vacant due to relocation. This functional differentiation of land use was closely interrelated with general political trends such as "selection and concentration" and intensification of agricultural competitiveness against the background of financial deterioration and Trans-Pacific Partnership negotiations since the late 1990s. Put shortly, the reconstruction process in this area was an extension and acceleration of existing trends as a whole.

However, there is a unique agricultural land-use system and related community organization rooted in the peculiar history and natural environment of the coastal area. Existing disaster reconstruction policies have not paid sufficient attention to such historical contexts. Although the "multifunctionality of agriculture" is emphasized as a new ideal in current agricultural policies, it has been overlooked in disaster reconstruction policies. Hence, vulnerabilities such as urban flooding and the decline of disaster subcultures were newly created. In other words, disaster studies should pay careful attention to the tensions between wider political trends and local-historical contexts. Such a viewpoint is significant not only for disaster studies, but also for environmental studies in general.

\section{Notes}

1) This survey was conducted from May to August 2018, and targeted 573 communities (neighborhood association districts) in 10 affected municipalities in Miyagi prefecture, as described below.

\begin{tabular}{lccc}
\hline Municipality & $\begin{array}{c}\text { Number of } \\
\text { surveys } \\
\text { distributed }\end{array}$ & $\begin{array}{c}\text { Valid } \\
\text { responses }\end{array}$ & $\begin{array}{c}\text { Collection } \\
\text { rate }\end{array}$ \\
\hline Kesennuma city & 204 & 106 & $52.0 \%$ \\
Minamisanriku town & 75 & 34 & $45.3 \%$ \\
Onagawa town & 33 & 25 & $75.8 \%$ \\
Ishinomaki city & 87 & 62 & $71.3 \%$ \\
Higashimatsushima city & 69 & 38 & $55.1 \%$ \\
Shichigahama town & 16 & 8 & $50.0 \%$ \\
Natori city & 21 & 12 & $57.1 \%$ \\
Iwanuma city & 28 & 12 & $42.9 \%$ \\
Watari town & 15 & 11 & $73.3 \%$ \\
Yamamoto town & 25 & 16 & $64.0 \%$ \\
\hline Total & 573 & 324 & $56.5 \%$ \\
\hline
\end{tabular}




\section{References}

1 I. Davis and D. Alexander, Recovery from Disaster. Routledge (2016)

2 N. R. Britton, "National Planning and Response," H. Rodriguez, E. L. Quarantelli, R. R. Dynes eds., Handbook of Disaster Research. Springer, pp. 347367 (2007)

3 S. Tanaka, Y. Kuroda, N. Yokota, A. Oyane, The Great East Japan Earthquake: Disaster Risk Reduction and Disaster Relief. Yuhikaku (2019)

4 K. Ueda and H. Torigoe, "Why do Victims of the Tsunami Return to the Coast?," International Journal of Japanese Sociology, 9, pp. 21-29 (2012)

5 T. Kawamura, T. Okamoto, K. Yoshino eds., Regeneration from "3.11". Ochanomizu Shobo (2013)

6 K. Hasegawa, T. Hobo, H. Ozaki, Recovery from the Great East Japan Earthquake at the Crossroad. University of Tokyo Press (2016)

7 Kansai University Faculty of Societal Safety Sciences, The Great East Japan Earthquake: Evaluation after 5 Years. Minerva Shobo (2016)

8 H. Yoshino and M. Kato eds., The Great East Japan Earthquake: Reconstruction and Prospect. Yuhikaku (2019)

9 J. K. Mitchell, N. Devine, K. Jagger, “A Contextual Model of Natural Hazard," Geographical Review, 79(4), pp. 391-409 (1989)

10 E. R. Wolf, "Distinguished Lecture: Facing Power Old Insights, New Questions," American Anthropologist, 92(3), pp. 586-596 (1990)

11 A. Oliver-Smith, "Global Changes and the Definition of Disaster," E. L. Quarantelli ed., What Is a Disaster?. Routledge, pp. 177-194 (1998)

12 P. Steinberg and R. Shields eds., What is a City? Rethinking the Urban after Hurricane Katrina. The University of Georgia Press (2008)

13 R. J. Samuels, 3.11: Disaster and Change in Japan. Cornell University Press (2013)

14 J. Gottmann, Megalopolis. The Twentieth Century Fund Inc. (1961)

15 J. Coaffee and P. Lee, Urban Resilience. Palgrave (2016)

16 Miyagi Prefecture, History of Agricultural Land Development in Miyagi Prefecture. (1994) (in Japanese)

17 Watari Town, History of Watari Town: Volume 2. (1977) (in Japanese)

18 Yamamoto Town, History of Yamamoto Town: Volume 2. (1986) (in Japanese)

19 Watari Town, History of Watari Town: Contemporary History. (2008) (in Japanese)

20 Yamamoto Town, History of Yamamoto Town: Volume 3. (2005) (in Japanese)

21 S. Shogenji, Agriculture and Humans. Iwanami Shoten (2013) (in Japanese)

22 N. Fukuyo, Building Resilient Community. Nihon Keizai Hyoronsha (2020) (in Japanese)

23 M. Mochizuki, Sociology of Disaster Reconstruction and Life. Ochanomizu Shobo (2020) (in Japanese)

24 D. E. Wenger and J. M. Weller, "Disaster Subculture: The Cultural Residues of Community
Disasters," Preliminary Papers; 9, Disaster Research Center, pp. 1-18 (1973) 